\title{
Pemrograman Rumah Sakit Medika
}

NAMA : Heri Fransetia

NPM : 19411049

PRODI : SISTEM INFORMASI

FAKULTAS : Ilmu Komputer

EMAIL : herifrans007@gmail.com

\section{SOAL TUGAS :}

1. Buatlah Program dengan ketentuan sebagai berikut :

Input :

kode pasien $=$ PS0003

Kode Kamar $=\mathbf{4 4 4 4 4}$

Lama Menginap $=5$ hari

Kode Dokter $=$ DK003

\begin{tabular}{|l|l|l|}
\hline Kode Pasien & Status Pasien & Biaya Daftar Pasien \\
\hline PS0001 & Pasien Baru & Rp. 500.000 \\
\hline PS0002 & Pasien Lama & Rp. 400.000 \\
\hline PS0003 & Pasien BPJS & Rp. 300.000 \\
\hline PS0004 & Pasien Askes & Rp. 200.000 \\
\hline
\end{tabular}

\begin{tabular}{|l|l|l|}
\hline Kode Kamar & Nama Kamar & Biaya Kamar \\
\hline 1111 & Kamar Melati & Rp. 1.000 .000 \\
\hline 2222 & Kamar Mawar & Rp. 2.000 .000 \\
\hline 3333 & Kamar Dahlia & Rp. 3.000.000 \\
\hline 4444 & Kamar Anggrek & Rp. 4.000 .000 \\
\hline 5555 & Kamar Tulip & Rp. 5.000.000 \\
\hline
\end{tabular}

\begin{tabular}{|l|l|l|}
\hline Kode Dokter & Nama Dokter & Biaya Pemeriksaan \\
\hline DK001 & DR. Andi & Rp. 500.000 \\
\hline DK002 & DR. Joko & Rp. 400.000 \\
\hline DK003 & DR. Karni & Rp. 300.000 \\
\hline DK004 & DR. Amin & Rp. 200.000 \\
\hline DK005 & DR. Udin & Rp. 100.000 \\
\hline
\end{tabular}

\begin{tabular}{|l|l|}
\hline Lama Menginap & Diskon \\
\hline$>10$ Hari & $50 \%$ dari Biaya Kamar \\
\hline$>8$ Hari & $40 \%$ dari Biaya Kamar \\
\hline$>6$ Hari & $30 \%$ dari Biaya Kamar \\
\hline$>4$ Hari & $20 \%$ dari Biaya Kamar \\
\hline$>+1$ & $10 \%$ dari Biaya Kamar \\
\hline
\end{tabular}


Biaya daftar Pasien

Nama Kamar

Biaya Kamar

Nama Dokter

Biaya Pemeriksaan

Diskon

Total Bayar

\section{SOURCE CODE / KODING PROGRAM (KETIK DIBAWAH INI)}

public class BiayaRS\{

public static void main (String []args)\{

String KodePasien = "PS0003";

int KodeKamar = 4444;

int LamaMenginap = 5;

String KodeDokter = "DK003";

String StatusPasien;

String NamaKamar;

String NamaDokter;

double BiayaDaftarPasien;

double BiayaPemeriksaan;

double BiayaKamar;

double TotalBayar;

double Diskon;

if(KodePasien == "PS0001")\{

StatusPasien = "Pasien Baru";

BiayaDaftarPasien = 500000;

\}

else if(KodePasien == "PS0002")\{

StatusPasien = "Pasien Lama";

BiayaDaftarPasien = 400000;

\}

else if(KodePasien == "PS0003")\{

StatusPasien = "Pasien BPJS";

BiayaDaftarPasien $=30000$;

\}

else \{

StatusPasien = "Pasien ASKES";

BiayaDaftarPasien = 200000;

\} 


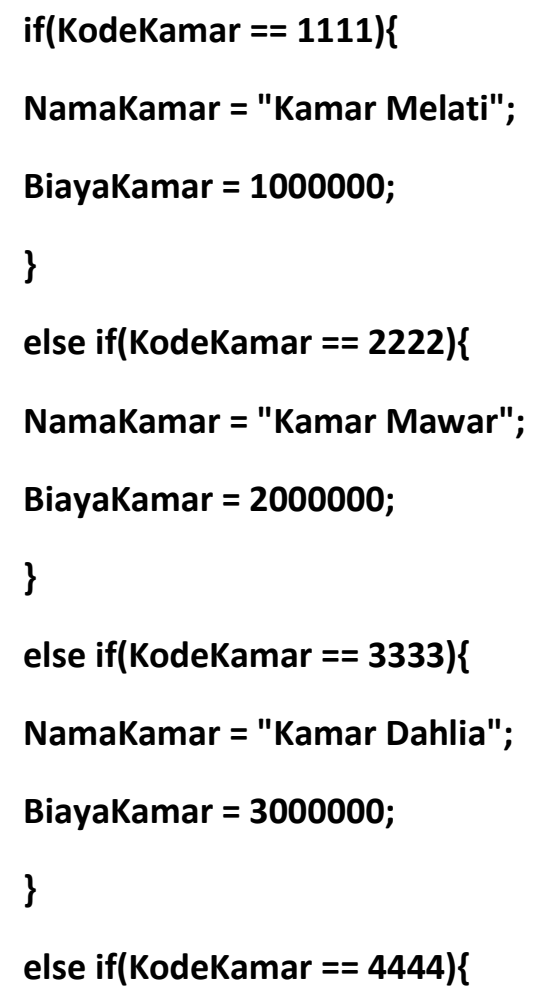


else \{

NamaDokter = "Dr.Udin";

BiayaPemeriksaan = 100000;

\}

if(LamaMenginap $>=10)\{$

Diskon = BiayaKamar * 0.5;

\}

else if(LamaMenginap $>=8)\{$

Diskon = BiayaKamar * 0.4;

\}

else if(LamaMenginap >= 6)\{

Diskon $=$ BiayaKamar $*$ 0.3

\}

else if(LamaMenginap $>=4)\{$

Diskon = BiayaKamar $*$ 0.2;

\}

else if(LamaMenginap >= 1)\{

Diskon $=$ BiayaKamar $*$ 0.1;

\}

else \{

Diskon= ;

\}

TotalBayar $=$ BiayaDaftarPasien + BiayaKamar + BiayaPemeriksaan - Diskon;

System.out.printIn("Kode Pasien = "+ KodePasien);

System.out.printIn("Status Pasien = "+ StatusPasien);

System.out.printIn("Biaya Daftar Pasien = Rp."+ BiayaDaftarPasien);

System.out.printIn("Kode Kamar = "+ KodeKamar);

System.out.printIn("Nama Kamar = "+ NamaKamar);

System.out.printIn("Biaya Kamar = Rp."+ BiayaKamar);

System.out.printIn("Kode Dokter = "+ KodeDokter);

System.out.printIn("Nama Dokter = "+ NamaDokter);

System.out.printIn("Biaya Pemeriksaan = Rp."+ BiayaPemeriksaan);

System.out.printIn("Diskon = Rp."+ Diskon);

System.out.printIn("Total Bayar = Rp."+ TotalBayar); 


\section{PENJELASAN SOURCE CODE (KETIK DIBAWAH INI)}

1. Membuat nama class untuk memulai pengcodingan program. Contoh : BiayaRumahSakit

2. Ketik " public static void main (String [largs)\{ "untuk memanggil variabel class dan menjalankan pengetikan codingan program pada java.

3. Lalu masukkan variabel dan inputan yang diminta, (Dengan menggunakan tipe data yang sesuai dengan kebutuhan kita inginkan).

Contoh : String KodePasien = "PS003";

int KodeKamar = 4444;

int LamaMenginap = 5;

String KodeDokter = "DK003";

4. Setelah inputan dimasukkan, lalu masukkan lagi variabel berikut hasil output yang nantinya akan diminta, (Tentunya harus menggunakan tipe data yang sesuai dengan kebutuhan kita inginkan).

Contoh : String StatusPasien;

double BiayaDaftarPasien;

String NamaKamar;

double BiayaKamar;

String NamaDokter;

double BiayaPemeriksaan;

double Diskon;

double TotalBayar;

5. Lalu, kita codingkanlah tabel-tabel diatas. (Namun, karena kondisi yang dibutuhkan juga lebih dari 2 kondisi, maka guanakanlah if dan else if , agar hasil outputnya sesuai dengan kebutuhan kita).

Contoh : if(KodePasien == "PS0001")

StatusPasien = "Pasien Baru";

BiayaDaftarPasien $=\mathbf{5 0 0 0 0 0}$;

\}else if(KodePasien == "PS0002")\{

StatusPasien = "Pasien Lama";

BiayaDaftarPasien $=400000$;

\}else if(KodePasien == "PS0003")\{

StatusPasien = "Pasien BPJS";

BiayaDaftarPasien $=300000$;

\}else\{

StatusPasien = "Pasien ASKES";

BiayaDaftarPasien = 200000;

\}

6. Lalu, setelah codingan tabel 1 selesai, kita codingkanlah lagi tabel 2 yang diatas.

(Masih sama, karena kondisi yang dibutuhkan juga lebih dari 2 kondisi, maka guanakanlah if dan else if, agar hasil outputnya sesuai dengan kebutuhan kita). Contoh : if (KodeKamar $==1111)\{$

NamaKamar = "Kamar Melati";

BiayaKamar = 1000000;

\}else if(KodeKamar $==\mathbf{2 2 2 2})\{$

NamaKamar = "Kamar Mawar";

BiayaKamar $=2000000$; 
\}else if $($ KodeKamar $==3333)\{$

NamaKamar = "Kamar Dahlia";

BiayaKamar $=3000000$;

\}else if $($ KodeKamar $==4444)\{$

NamaKamar = "Kamar Anggrek";

BiayaKamar $=4000000$;

\}else \{

NamaKamar = "Kamar Tulip";

BiayaKamar $=\mathbf{5 0 0 0 0 0 0}$;

\}

7. Lalu, setelah codingan tabel 1 dan 2 selesai, maka kita codingkanlah lagi tabel 3 yang diatas. (Masih sama, karena kondisi yang dibutuhkan juga lebih dari 2 kondisi, maka guanakanlah if dan else if , agar hasil outputnya sesuai dengan kebutuhan kita).

Contoh: if(KodeDokter $==$ "DK001") \{

NamaDokter = "Dr.Andi";

BiayaPemeriksaan $=500000$;

\}else if $($ KodeDokter $==$ "DK002" $)\{$

NamaDokter $=$ "Dr.Joko";

BiayaPemeriksaan $=400000$;

\}else if(KodeDokter $==$ "DK003" $)\{$

NamaDokter = "Dr.Karni";

BiayaPemeriksaan = 300000;

\}else if $($ KodeDokter $==$ "DK004" $)\{$

NamaDokter = "Dr.Amin";

BiayaPemeriksaan $=200000$;

\}else\{

NamaDokter = "Dr.Udin";

BiayaPemeriksaan = 100000;

\}

8. Lalu, setelah codingan tabel 1,2 dan 3 selesai, maka kita codingkanlah lagi tabel 4 yang diatas. (Masih sama, karena kondisi yang dibutuhkan juga lebih dari 2 kondisi, maka guanakanlah if dan else if , agar hasil outputnya sesuai dengan kebutuhan kita). Contoh : if (LamaMenginap $>=10)\{$

Diskon $=$ BiayaKamar $* 0.5$;

\}else if(LamaMenginap $>=8)\{$

Diskon $=$ BiayaKamar $* 0.4$;

\}else if(LamaMenginap >= $)\{$

Diskon = BiayaKamar $* 0.3$;

\}else if(LamaMenginap $>=4)\{$

Diskon = BiayaKamar $*$ 0.2;

\}else if(LamaMenginap $>=1)\{$

Diskon $=$ BiayaKamar $* 0.1$;

\}else\{

Diskon = 0;

$$
\text { \} }
$$


9. Untuk mengakhiri codingan yang telah kita buat pada tabel ke-1,2,3 dan 4 diatas.

Langkah selanjutnya adalah memasukkan code dibawah berikut untuk menentukan:

TotalBayar $=$ BiayaDaftarPasien + BiayaKamar + BiayaPemeriksaan - Diskon;

System.out.println("Kode Pasien = "+ KodePasien);

System.out.println("Status Pasien = "+ StatusPasien);

System.out.println("Biaya Daftar Pasien = Rp."+ BiayaDaftarPasien);

System.out.println("Kode Kamar = "+ KodeKamar);

System.out.println("Nama Kamar = "+ NamaKamar);

System.out.println("Biaya Kamar = Rp."+ BiayaKamar);

System.out.println("Kode Dokter = "+ KodeDokter);

System.out.println("Nama Dokter = "+ NamaDokter);

System.out.println("Biaya Pemeriksaan = Rp."+ BiayaPemeriksaan);

System.out.println("Diskon = Rp."+ Diskon);

System.out.println("Total Bayar = Rp."+ TotalBayar);

\} 


\section{FLOWCHART PROGRAM}

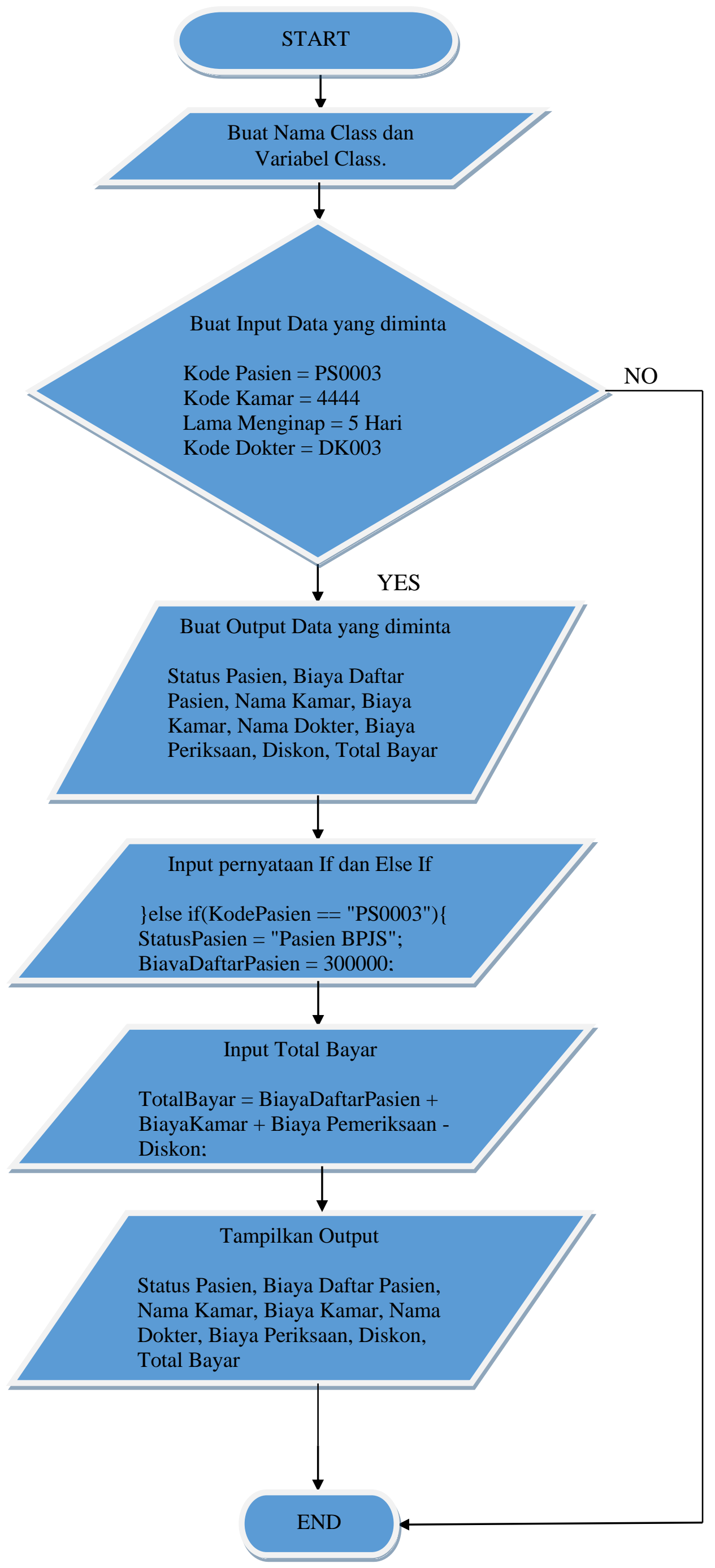




\section{REFERENSI :}

Endra, R. Y. (2019, October 29). Belajar Mudah Algoritma dan Pemograman Java. Retrieved from osf.io/v7yfn

Endra, R. Y. (2019, October 29). Internet of Things. Retrieved from osf.io/4h8sf 